\title{
Glossary of Terms
}

\section{Hip Hop}

The term 'hip hop' was coined in the late 1970s, possibly in New York City, to refer to a set of cultural, artistic, spiritual and intellectual practices used for self-expression and the circulation of knowledge. These practices include, among others, graffiti writin, rappin, beatboxin, deejayin, samplin, street dancin, breakin, street knowledge, informal education and entrepreneurship. These practices developed out of earlier Black and Latinx traditions, for instance Mambo dancing, playing the dozens and participation in the Nation of Islam/Nation of Gods and Earths (Five Percenters). The emergence of hip hop in the South Bronx is inextricably linked to the socioeconomic disenfranchisement and cultural abandonment that took place in the post-industrial inner-cities of North America (for historical accounts of the developments of hip hop, see Chalfant, 2006; Chang, 2005; Rose, 1994; Toop, 1991). The Bronx represents a universal myth that can be used by global hip hop practitioners to imagine old school authenticity in their local contexts.

The two terms 'hip' and 'hop' are themselves important signifiers for the practitioners' understanding of the culture (see also Seti X's narrative in Chapter 6). One of the most famous ambassadors of hip hop, the self-proclaimed teacha of hip hop, KRS-One (2007), in his song Hip Hop Lives (featuring Marley Marl), defines 'hip' as 'a form of intelligence' and 'hop' as 'a form of movement', and therefore 'hip hop' as 'intelligent movement' (the full lyrics can be viewed here: https://genius.com/ Krs-one-and-marley-marl-hip-hop-lives-i-come-back-lyrics).

Whereas the most widely circulating 'definitions' of hip hop derive from those organic intellectuals who were produced by US-American hip hop culture (like KRS-One), global hip hop practitioners constantly negotiate the meanings of such key cultural signifiers and transform them 
so they become real in the local context. Much of this book is about understanding how my Delhi-based youthful participants, as well as hip hop travellers who are engaging with Delhi's hip hop scene, negotiate what it means to be and do hip hop in their local context.

\section{Hip Hop Heads}

When referring to my ethnographic interlocutors, as well as hip hop practitioners more generally, I use the word 'heads' or 'hip hop heads'. This is emic hip hop terminology that my participants often used themselves. A head is someone who is committed to hip hop culture and has a deep interest in and knowledge of the history and practices of hip hop. Similarly, Williams and Stroud (2013: 4, n2) write, that hip hop heads are 'knowledgeable individuals in the Hip-Hop culture who are not only the core and long-term members [...] but practice, transmit the knowledge and preserve the aesthetic and artistic use of deejaying, emceeing, b-boying, graffiti writing and knowledge of the self'. The term 'heads' also connotes a mindfulness, or headfulness, and emphasises that artistic and physical practices are always accompanied by the pursuit of knowledge, wisdom, overstandin, consciousness and upliftment. Furthermore, in line with the theory of voice developed in this book, a head can be regarded as the locus or centre in which a multitude of voices are produced and understood. A head contains all the parts of the body necessary to communicate effectively (mouth and vocal tract, ears and brain, as well as facial expressions which are important to contextualise communication).

\section{The Five Elements}

Hip hop heads usually describe their culture as consisting of five elements, or five pillars, although there is hardly any consensus of how these elements could be defined exactly and where their boundaries lie. Whereas the first four elements are artistic and physical practices that are acquired through informal pedagogy and mediatised circulation, the fifth element, also known as the supreme element, unites the first four elements and mythologises hip hop as a culture, as discussed in more detail in Chapter 8 (see also Gosa, 2015). The five elements are the following:

(1) Breakin: The artistic, acrobatic and stylish body movements danced to the loop of a drum break (also known as breakdancing, rockin, street dancin, b-boyin and b-girlin, sometimes also includes other forms of hip hop dance like poppin, lockin, clownin and electric boogie). 
(2) Graffiti writin: The painting of large, often convoluted and intricate, letters onto public walls, vehicles and trains using spray cans and other painting materials (also known as sprayin, aerosol art, sometimes also includes street art).

(3) Deejayin: The dynamic playin, jugglin, scratchin and mixin of vinyl records with two turntables and a mixer (also known as DJing, turntablism, spinnin, sometimes also includes samplin, producin).

(4) Emceein: The rhythmic speakin of intelligent rhymes on a beat (also known as MCing, rappin, spittin, also includes beatboxin)

(5) Knowledge and overstandin: The spirited pursuit and intelligent application of reflexive thought (also known as understanding, consciousness, knowledge of self, philosophy, wisdom, respect, unity and upliftment).

In this book I graphemically represent the final morpheme in the names of the five elements as <in>, as opposed to a more standardised English representation of <ing $>$. This 'dropping' of the graphemic $<\mathrm{g}>$, of course indexes an allophonic substitution from [II] to [In] in final '-ing' morphemes in multisyllabic words. With this I wish to index African American urban ways of speaking (Green, 2002) to situate and pay respect to the origins of these elements (for a use of $<$ in $>$ in final morphemes in academic writing, see Alim, 2006a; Smitherman, 1977, as also discussed in Chapter 3 of this book). [In] is of course also commonly used across the English-speaking world in informal speech and typically used frequently by working-class male speakers (Tagliamonte, 2012: 187; Trudgill, 1972). By recognising the indexicalities and linguistic ideologies of this well-researched sociolinguistic variable, I use it for my own codemeshing (Canagarajah, 2013) in my writin, to align my authorship with the non-standard and informal intellectualism and spirituality of hip hop, as well as index the predominance of masculine ideologies in hip hop culture more generally, and specifically in my ethnographic experiences. 